\title{
COVID-19 mRNA vaccine and antibody response in lactating women: a prospective cohort study
}

\author{
Nadia Charepe ${ }^{1,2^{*}}$, Juliana Gonçalves ${ }^{3,4}$, A. Margarida Juliano ${ }^{3,4}$, David G. Lopes ${ }^{2,5}$, Helena Canhão 1,2,5, \\ Helena Soares ${ }^{2,3,4}$ and e Fátima Serrano ${ }^{1,2}$
}

\begin{abstract}
Background: Immunological protection via breastfeeding is well known. The immunological profile of human milk changes during lactation. No clinical trials have been conducted in lactating women with the newest mRNA vaccines against SARS- CoV-2. A Few studies have shown the presence of antibodies in breastmilk after vaccination. The aim of this work is to study possible antibodies transfer via breastmilk and also the immunological characteristics of lactating women compared to non-lactating women, after using the BNT162b2 Pfizer vaccine.

Methods: This is a prospective cohort study with a convenience homogenous sample of 24 healthcare workers (14 lactating and 10 non-lactating women) enrolled at the time of COVID-19 vaccination. Clinical data was registered in a questionnaire. Titers of SARS-CoV-2 spike IgG, IgA and IgM were quantified in post vaccination blood and human milk. Antibody quantification was performed by an in-house ELISA to SARS-CoV-2 trimeric spike protein.

Results: All women showed immunity after vaccination with positive antibodies for $\lg M$, IgA and IgG antibodies. The dominant serum antibody response was lgG. Modest levels of antibodies in breastmilk of lactating mothers were observed in this study, especially lgG in $42.9 \%$. There was a moderate association between higher titers of $\lg G$ and a longer duration of breastfeeding $(R=0.55, p=0.041)$.

Conclusions: Evidence of antibody transfer in human milk after COVID-19 vaccination is scarce. The presence of antibodies in human milk is reported, but immunization through breastfeeding is still to be established.
\end{abstract}

Keywords: Breastfeeding, Covid-19, mRNA vaccination, Antibodies

\section{Background}

In the first months of life, neonates are at greater risk of infections, due to their immature immune system and breastfeeding will boost immunological responses [1]. Additionally, breastfeeding is proven to be effective against acute and prolonged infections, and has an influence on infant immune response after mother's vaccine immunization

\footnotetext{
* Correspondence: nadia.b.charepe@edu.nms.unl.pt

'Centro Hospitalar Universitário de Lisboa Central (CHULC), Lisboa, Portugal

${ }^{2}$ Comprehensive Health Research Centre, NOVA Medical School, Universidade NOVA de Lisboa, Lisboa, Portugal

Full list of author information is available at the end of the article
}

[2]. Secretory IgA (SIgA) represents $90 \%$ of the antibodies in human milk, followed by IgM and IgG antibodies [1]. For this reason, and for its biological properties, SIgA is very important, as it is essential in defending mucous membranes [1]. Nevertheless, specific characteristics of lactating mothers may influence the kinetics of human milk antibodies due to the differences of previous infections (time since preexisting disease immunity), age, genetic factors, and individual immune response [3].

The arrival of COVID-19 vaccines, specifically mRNA vaccines against SARS-CoV-2 such as BNT162b2 Pfizer, has raised the question whether they are safe for use in

(c) The Author(s). 2021 Open Access This article is licensed under a Creative Commons Attribution 4.0 International License, which permits use, sharing, adaptation, distribution and reproduction in any medium or format, as long as you give appropriate credit to the original author(s) and the source, provide a link to the Creative Commons licence, and indicate if changes were made. The images or other third party material in this article are included in the article's Creative Commons licence, unless indicated otherwise in a credit line to the material. If material is not included in the article's Creative Commons licence and your intended use is not permitted by statutory regulation or exceeds the permitted use, you will need to obtain permission directly from the copyright holder. To view a copy of this licence, visit http://creativecommons.org/licenses/by/4.0/ The Creative Commons Public Domain Dedication waiver (http://creativecommons.org/publicdomain/zero/1.0/) applies to the data made available in this article, unless otherwise stated in a credit line to the data. 
the pregnant population and lactating women, because no clinical trials were conducted on these groups. In the general population, mainly participants without previous SARS-CoV-2 infection, there was a $90 \%$ efficacy at preventing severe symptoms after two doses were administered [4]. The academy of Breastfeeding Medicine does not recommend cessation of breastfeeding for individuals who are vaccinated against COVID-19 [5]. The American college of obstetricians and gynecologists recommend that COVID-19 vaccines should be offered to lactating individuals as to non-lactating individuals [6]. The potential risks and benefits for these breastfed babies are still to be determined. Taking into account that vaccination during pregnancy against other viruses, such as influenza, was related to specific active antibody production throughout lactation, the same may happen in mRNA vaccines [7].

Gray et al, confirmed that the COVID-19 mRNA vaccines result in comparable humoral immune responses in lactating women to those observed in non-pregnant populations after studying 31 lactating women in a prospective cohort study. Antibodies and especially SARSCoV-2-specific IgG were found in breastmilk [8].

The objectives of this study were to evaluate the serological profile of lactating women compared to nonlactating women, after immunization with the BNT162b2 Pfizer vaccine, in a cohort of healthcare workers, and study antibody transfer via breastmilk.

\section{Materials and methods}

This was a prospective cohort study undertaken between 27 December 2020 and 19 February 2021, with a convenience homogeneous sample of 24 healthcare workers (14 lactating and 10 non-lactating women) enrolled at the time of COVID-19 vaccination with BNT162b2 Pfizer/BioNTech after advertising the study.

Eligible participants were: 1) lactating and nonlactating women who underwent vaccination with BNT162b2 Pfizer; 2) older than 18 years old and able to provide informed consent.

Demographic data, date and type of delivery, breastfeeding details, timing of COVID-19 vaccine doses, postvaccination symptoms were assessed using a written questionnaire.

This study was reviewed and approved by the local ethics committee (NOVA Medical School) as per principles embodied in the Declaration of Helsinki. Written informed consent was given by all participants.

\section{Samples collection}

A blood sample was collected by venipuncture from all participants one to three weeks after the first and second dose of vaccine administration (accordingly with participants availability). Breastmilk from lactating women was collected on the same days of blood collection (after the first and second dose) and collected with breast pump into sterile containers, being the volume around 100-200 ml (Table 1).SD Standard Deviation

\section{Antibody quantification: Plasma and skim milk isolation}

Blood was diluted in PBS 1x (VWR), layered on top of biocoll (biowest) and centrifuged at 1200xg for $30 \mathrm{~min}$ without a break. Plasma was collected to cryotubes and stored at $-80^{\circ} \mathrm{C}$ ultra-low freezer until subsequent analysis.

Skim milk was stored in $-20^{\circ} \mathrm{C}$ freezer until further analysis. Both biospecimens were immediately processed and centrifuged at $3000 \mathrm{xg}$ for $30 \mathrm{~min}$ at room temperature. ELISA assay was performed based on the protocol [9] and modified as described in Gonçalves J et al [10].

Briefly, 96 well plates (Nunc) were coated with $50 \mu \mathrm{l}$ of trimeric spike protein at $0.5 \mu \mathrm{g} / \mathrm{mL}$ and incubated overnight at $4^{\circ} \mathrm{C}$. On the following day, the plate was washed three times with $0.1 \% \mathrm{PBS} /$ Tween20 (PBST) using an automatic plate washer (ThermoScientific). Plates were blocked with $3 \%$ of bovine serum albumin (BSA) diluted in $0.05 \% \mathrm{PBS} / \mathrm{T}$ and incubated for 1 hour at room temperature. Samples were diluted using 3-fold dilutions series, starting at 1:50 and ending at 1:10,9350 in $1 \%$ BSA-PBST/T and incubated for 1 hour at room temperature. As previously, Plates were washed three times and goat anti-human IgA/IgG/IgM-HRP secondary antibodies (abcam, ab97225/ab97215/ab97205) were added at 1:25,000 and incubated for 30 minutes at room temperature. Plates were washed three times and incubated for around $7 \mathrm{~min}$ with $50 \mu \mathrm{l}$ of TMB substrate (BioLegend). The reaction was stopped with $25 \mu \mathrm{l}$ of $1 \mathrm{M}$ phosphoric acid (Sigma) and read at $450 \mathrm{~nm}$ on a plate reader (BioTek).

Each plate contained 6 calibrators samples from two high-, two medium-, and two low- antibody producer from adult individuals collected at Fernando Fonseca Hospital that were confirmed positive for SARS-CoV-2 by RT-PCR from nasopharyngeal and/or oropharyngeal swabs in a laboratory certified by the Portuguese National Health Authorities [10]. For negative control we used pre-pandemic plasma samples obtained from healthy donors collected prior to July 2019 .

The endpoint titer was defined as the last dilution before the absorbance dropped below $\mathrm{OD}_{450}$ of 0.15 . For samples that exceeded an $\mathrm{OD}_{450}$ of 0.15 at the last dilution $(1: 10,9350)$ the end-point titer was determined by interpolation [9]. Positive immune response (IgG, IgA and IgM) was considered when $\geq 150 \mathrm{UI} /$ $\mathrm{mL}$. We calculated IgG and IgA endpoint titers of SARS-CoV-2 positive individuals by serial 3 -fold dilution and classified end-point titers of 1:150 as low, 1: 
Table 1 Elapsed time (days) after the $1^{\text {st }}$ and $2^{\text {nd }}$ dose

\begin{tabular}{|c|c|c|c|c|c|}
\hline ID Lactating & 1st dose & 2nd dose & ID Non-Lactating & 1st dose & 2nd dose \\
\hline 1 & 10 & 10 & 15 & 22 & 10 \\
\hline 2 & 8 & 8 & 16 & 22 & 16 \\
\hline 3 & 8 & 10 & 17 & 22 & 10 \\
\hline 4 & 10 & 10 & 18 & 22 & 10 \\
\hline 5 & 13 & 13 & 19 & 22 & 10 \\
\hline 6 & 9 & 7 & 20 & 22 & 10 \\
\hline 7 & 8 & 9 & 21 & 22 & 10 \\
\hline 8 & 8 & 9 & 22 & 23 & 11 \\
\hline 9 & 7 & 10 & 23 & 23 & 11 \\
\hline 10 & 12 & 12 & 24 & 23 & 11 \\
\hline 11 & 10 & 11 & - & - & - \\
\hline 12 & 13 & 10 & - & - & - \\
\hline 13 & 8 & 7 & - & - & - \\
\hline 14 & 16 & 9 & - & - & - \\
\hline Mean (SD) & $9.5(2.6)$ & $10(1.7)$ & Mean (SD) & $22.0(0.5)$ & $10.0(1.9)$ \\
\hline
\end{tabular}

450 as moderate, and $\geq 1: 1.350$ as high antibody producers, as previously done [9].

\section{Statistical analyses}

Continuous variables were expressed as means, standard deviation and range, whilst categorical variables were shown as absolute frequencies and percentages. The study used IBM SPSS ${ }^{\circ}$ version 23 and RStudio software [11] for statistical analysis. Correlation analyses were performed using the Spearman coefficient. Experimental and control groups antibody levels were compared using the Wilcoxon-Mann-Whitney non-parametric test. Statistical significance was defined as $\mathrm{p}<0.05$.

\section{Results}

Participant's characteristics are presented in Table 2.

There were no differences between lactating and nonlactating women in terms of age, smoking habits or comorbidities. None of the participants reported a prior SARS-CoV-2 infection. There was no difference in post vaccination side effects when comparing lactating versus non lactating women $(p$-value $=0.618)$. The most commonly reported side effect was myalgia.

Delivery occurred at term in $92.8 \%(\mathrm{n}=13)$ of the lactating women and $64.3 \%(\mathrm{n}=9)$ had a vaginal delivery. Most lactating women had breastfed over a time period of 12-24 months at the time of the sample collection. Exclusive breastfeeding was registered in 2 cases. The weight of all infants at the time of the study was $\geq 50^{\text {th }}$ percentile.

All women have shown immunity after vaccination with positive serum antibodies after the second dose (Fig. 1). The dominant serum antibody response was
IgG, showing high levels in both lactating and nonlactating women. (Table 3) However, after the $1^{\text {st }}$ dose there were higher levels of serum IgG antibodies in the non-lactating group $(\mathrm{W}=112.5, p$-value $=0.00531)$.

Regarding lactating women, serum IgM and IgG isotypes increased after the $2^{\text {nd }}$ dose. IgA levels reduced slightly after the $2^{\text {nd }}$ dose, though there was great variation in individual values (Fig. 2).

The presence of antibodies in breastmilk was detected after vaccine administration. IgG was present in 7.1\% (1/ 14) after the $1^{\text {st }}$ dose and increased after the $2^{\text {nd }}$ dose to $42.9 \%(6 / 14)$. IgA response was present in 35.7\% (5/14) of milk samples after the $1^{\text {st }}$ dose, but showed a reduction to $21.4 \%(3 / 14)$ after the $2^{\text {nd }}$ dose. No IgM response was observed following the prime or boost. (Table 2)

When comparing IgA $\left(1^{\text {st }}\right.$ dose $)$ and IgG $\left(2^{\text {nd }}\right.$ dose $)$ levels between matched serum/milk, there was a tendency for an upward curve and a statistically significant association between IgG ( $2^{\text {nd }}$ dose) serum/milk when adjusting for maternal age and days after dose administration (Fig. 3).

We analyzed the relationship of breastfeeding duration and IgG/IgA response in the milk. Moderate positive correlation between the two variables (duration of breastfeeding and milk IgG after $2^{\text {nd }}$ dose) was found $(\mathrm{R}=0.55, p=0.041)$. Thus, higher titers of IgG are associated with longer breastfeeding time (Fig. 4a) However, when adjusted for maternal age and time since the $2^{\text {nd }}$ dose, this correlation was no longer statistically significant. Additionally, the distribution of values for a) does not appear to be linear.

This is likely owing to the small number of observations which happened to have the same IgG titer 
Table 2 Participant's data

\begin{tabular}{|c|c|c|}
\hline Characteristics & Lactating women $(n=14)$ & Non-lactating women $(n=10)$ \\
\hline \multicolumn{3}{|l|}{ Maternal data } \\
\hline Age Median \pm SD & $33.7 \pm 4.95$ years & $34.5 \pm 10.6$ years \\
\hline (minimum, maximum) years & $26-44$ & $26-62$ \\
\hline Caucasian n (\%) & $14(100 \%)$ & $10(100 \%)$ \\
\hline Smoking habits n (\%) & $1(7.1 \%)$ & $1(10 \%)$ \\
\hline \multicolumn{3}{|l|}{ Comorbidities n (\%) } \\
\hline No Comorbidities & $8(57.1 \%)$ & $6(60 \%)$ \\
\hline Hypertension & $1(7.1 \%)$ & $1(10 \%)$ \\
\hline Asthma & $2(14.3 \%)$ & - \\
\hline Dyslipidaemia & $1(7.1 \%)$ & $1(10 \%)$ \\
\hline Thyroid disorders & $1(7.1 \%)$ & $1(10 \%)$ \\
\hline Beta thalassemia & $1(7.1 \%)$ & - \\
\hline Hodgkin lymphoma & - & $1(10 \%)$ \\
\hline \multicolumn{3}{|l|}{ Side effects post vaccination n (\%) } \\
\hline Myalgia & $8(57 \%)$ & $6(60 \%)$ \\
\hline Headache & $6(42.9)$ & $5(50 \%)$ \\
\hline Local pain & $5(35.7 \%)$ & $4(40 \%)$ \\
\hline Nausea & $2(14.3 \%)$ & $2(20 \%)$ \\
\hline Fever & $1(7.1 \%)$ & $2(20 \%)$ \\
\hline Photophobia & $1(7.1 \%)$ & $2(20 \%)$ \\
\hline Tiredness & - & $3(30 \%)$ \\
\hline Arthralgia & $1(7.1 \%)$ & $2(20 \%)$ \\
\hline Arm numbness & $1(7.1 \%)$ & - \\
\hline Delivery data & & NA \\
\hline GA at delivery Median \pm SD (Range) & $38.5 \pm 1.7$ weeks (range 34-41) & \\
\hline \multicolumn{3}{|l|}{ Mode of Delivery n (\%) } \\
\hline Caesarean & $5(35.7 \%)$ & \\
\hline Vaginal & $9(64.3 \%)$ & \\
\hline Infant and Breastfeeding data & & NA \\
\hline Birthweight (g) Median \pm SD & $3263 \pm 383(2460-3800)$ & \\
\hline Percentile at the time of vaccination & $65.5 \pm 17$ (range 50-97) & \\
\hline \multicolumn{3}{|l|}{ Breastfeeding duration n (\%) } \\
\hline$\leq 2-12$ months & $6(42.85 \%)$ & \\
\hline$\geq 12-24$ months & $8(57.14 \%)$ & \\
\hline Exclusive breastfeeding & $2(14.28 \%)$ & \\
\hline
\end{tabular}

GA Gestational age, NA Not applicable

values. There was a non-significant negative association between $\operatorname{IgA}\left(2^{\text {nd }}\right.$ dose) and duration of breastfeeding (Fig. 4b).

All women kept breastfeeding post vaccination. Only one infant showed different behaviour after maternal vaccination (somnolence). There was a case of tandem breastfeeding (brothers) not related to increase transfer of antibodies to the milk.

\section{Discussion}

Pregnant and lactating women were excluded from initial clinical trials for anti-SARS-CoV-2 vaccination, and many concerns, especially safety issues, arose related to vaccination in this specific population. To our knowledge, only a few studies have addressed this topic [1215]. To date, there are no robust studies regarding the safety and efficiency of vaccination in lactating women. 
a)

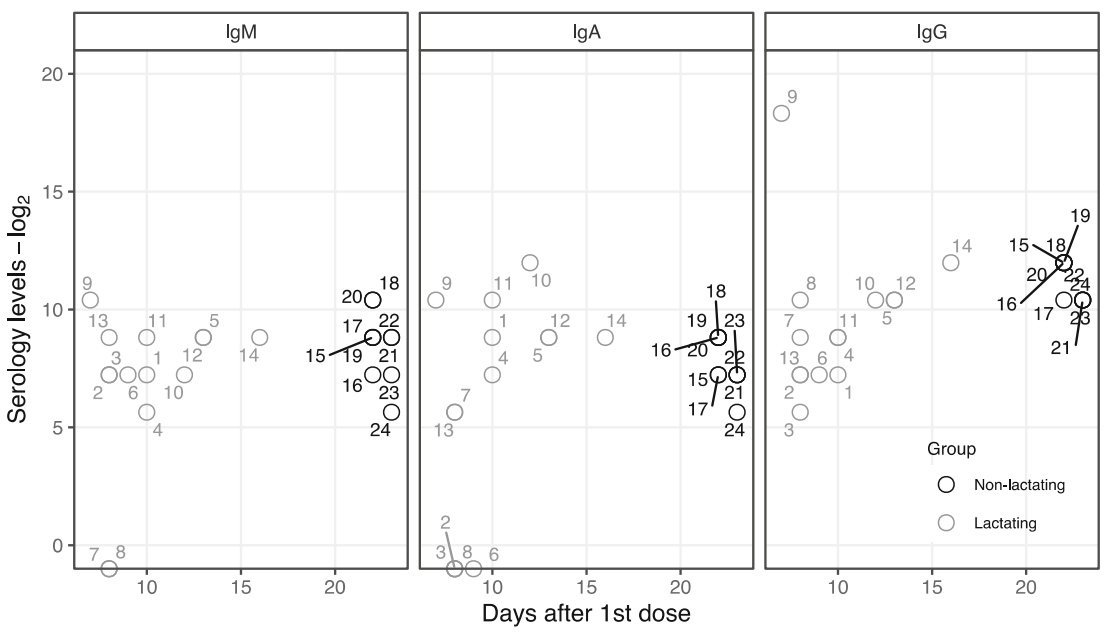

b)

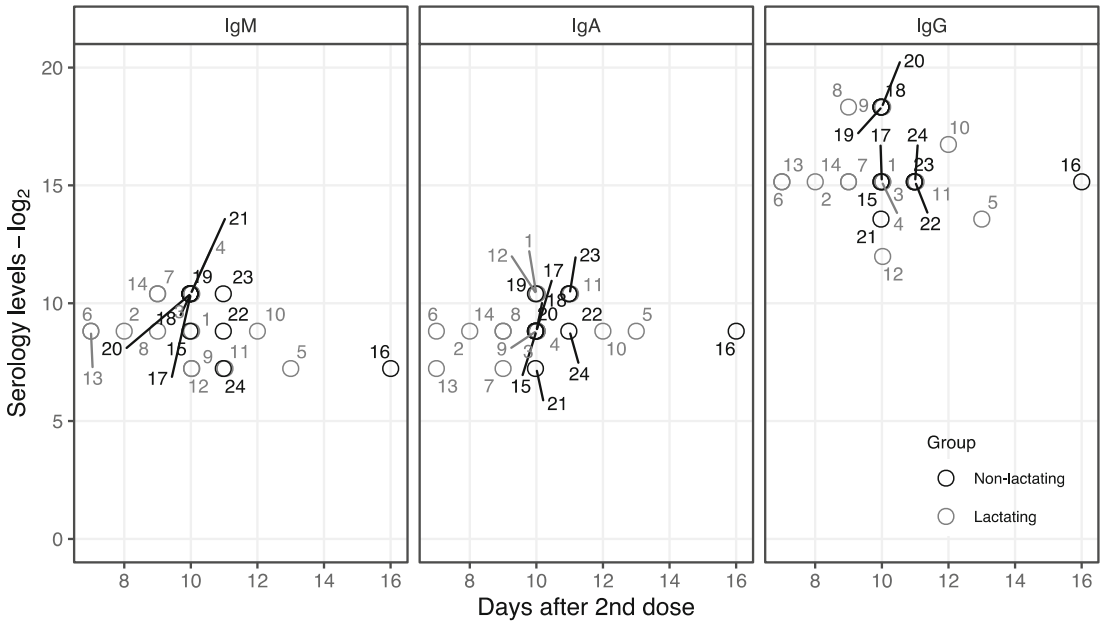

c)

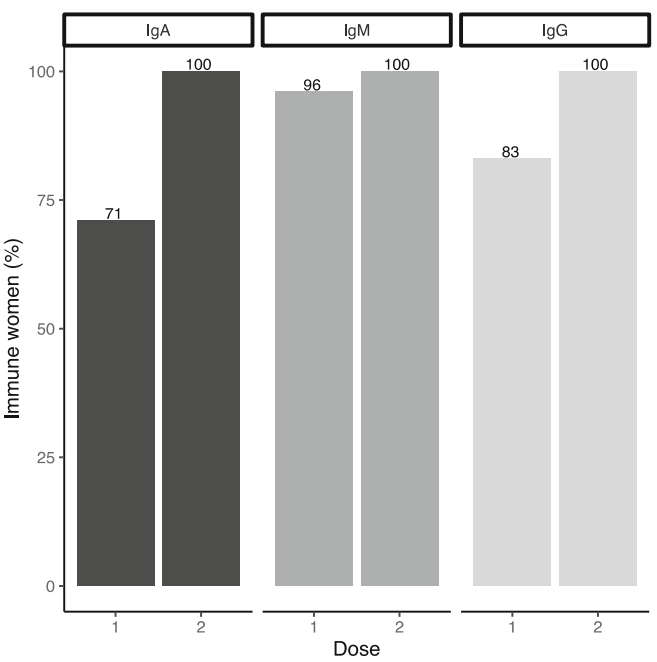

Fig. 1 Distribution of titers over elapsed time (days) after the first dose $\mathbf{a}$ and second dose $\mathbf{b}$ of the BNT162b2 Pfizer vaccine for lactating ( $n=14$ ) and non-lactating $(n=10)$ women. c Percentage of women with vaccine-induced antibodies (antibody titers $\geq 150)$ c) 
Table 3 Antibody titers among lactating and non-lactating women

\begin{tabular}{|c|c|c|c|c|}
\hline \multirow{2}{*}{$\begin{array}{l}\text { Antibodies titers } \\
\text { Blood (Mean) }\end{array}$} & \multicolumn{2}{|c|}{ Lactating women $(n=14)$} & \multicolumn{2}{|c|}{ Non-lactating women $(n=10)$} \\
\hline & $1^{\text {st }}$ dose $(U \mathrm{Ul} / \mathrm{mL})$ & $2^{\text {nd }}$ dose $(\mathrm{Ul} / \mathrm{mL})$ & $1^{\text {st }}$ dose $(\mathrm{UI} / \mathrm{mL})$ & $2^{\text {nd }}$ dose $(\mathrm{UI} / \mathrm{mL})$ \\
\hline $\lg G$ & 24250 & 79264 & 2700 & 121500 \\
\hline $\lg A$ & 880 (4 ND) & $600(2 \mathrm{ND})$ & 260 & 690 \\
\hline $\lg M$ & 366 & 621 & 530 & 930 \\
\hline \multicolumn{5}{|c|}{ Milk (titer range 150-1350) } \\
\hline $\lg G$ & $1(7.1 \%)$ & $6(42.9 \%)$ & NA & NA \\
\hline $\lg A$ & $5(35.7 \%)$ & $3(21.4 \%)$ & NA & NA \\
\hline $\lg M$ & ND & ND & NA & NA \\
\hline
\end{tabular}

ND not detected, NA not applicable

In the study of Golan et al, mRNA from anti-COVID vaccines was not detected in human breast milk, this strengthens the recommendation of maintaining breastfeeding after inoculation [16]. In a recent study of Friedman et al, there is evidence of a rapid production of vaccine-specific antibodies, both IgA and IgG and neutralizing capacity was proven [17]. Moreover, information is needed regarding antibody transfer to breastmilk and the ability of the infant to receive immunity via breastfeeding, response that is well established in other vaccines during pregnancy such as Influenza and Pertussis [18]. Due to the lack of information, our study aims to add scientific information, allowing future studies to develop.

In our cohort, the presence of serum antibodies after vaccine administration was documented in all women. In a non-infected population, vaccination with mRNA vaccines elicited spike antigen-specific IgA with similar kinetics of induction as IgG, although the levels of spike antigen-specific IgA decreased significantly over time [13]. We also documented a significant increase in IgG response after the second dose. On the other hand, IgA response decreased after the second dose. These results are comparable to previous studies $[12,13]$.
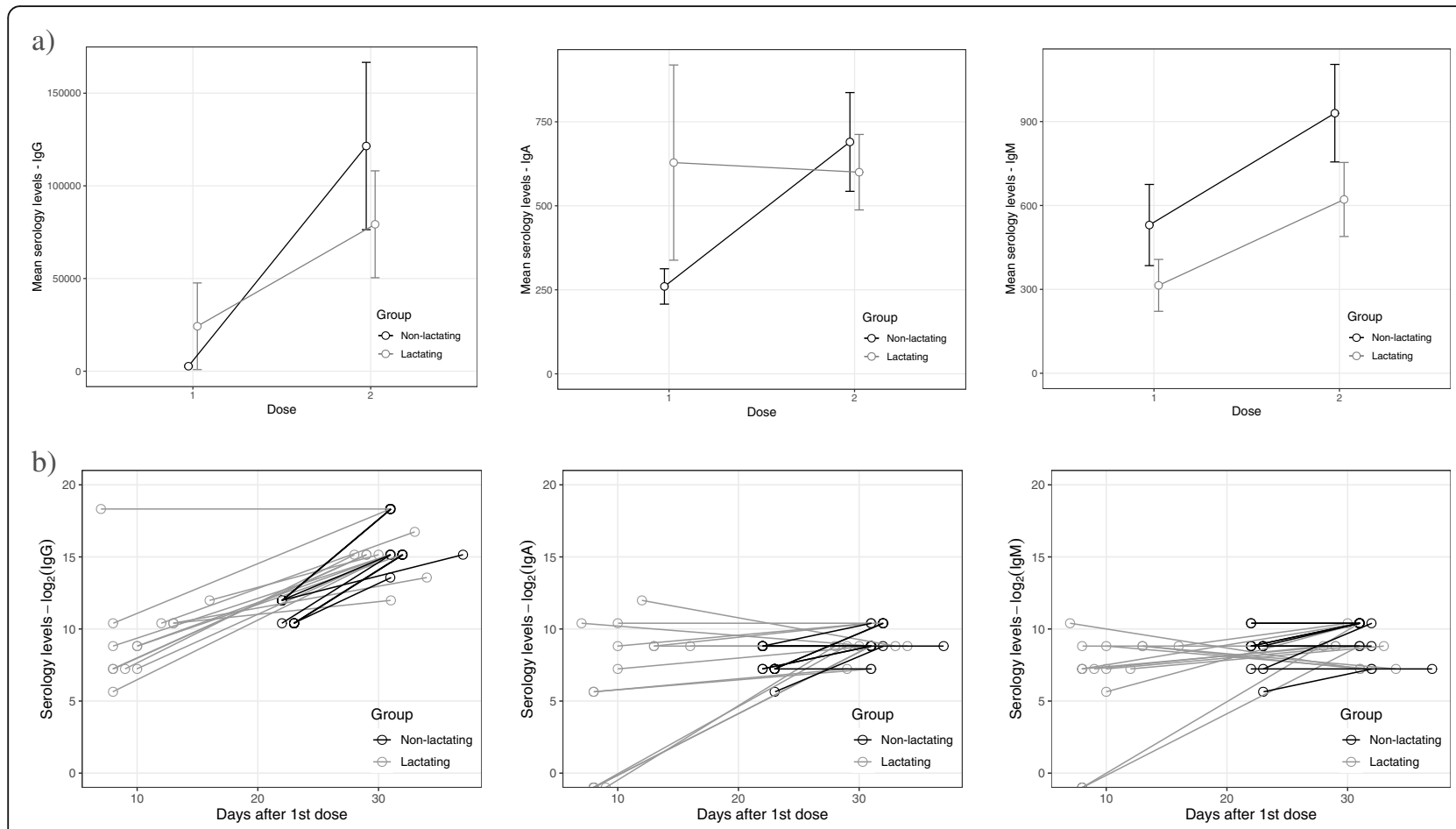

Fig. 2 Mean blood serology levels in lactating $(n=14)$ and non-lactating $(n=10)$ women after the first and second dose of BNT162b2 Pfizer vaccine a) Mean IgG, IgA, IgM isotypes (log2) over elapsed time from $1^{\text {st }}$ dose $\mathbf{b}$ ) Full sample $n=24$ 


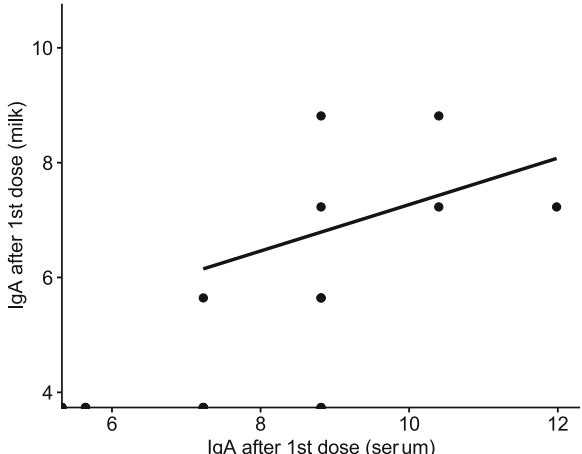

a)

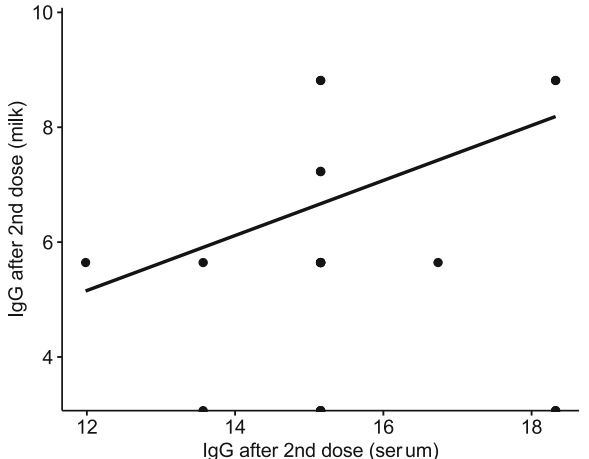

b)

Fig. 3 The Spearman coefficient of correlation (log_2 antibodies) between IgA ( $1^{\text {st }}$ dose) in milk and serum a, and lgG ( $2^{\text {nd }}$ dose) in milk and serum $\mathbf{b}$, adjusted for maternal age and time after the vaccine dose (days)

An increase in antibody titers in non-lactating women comparing to lactating women in our study could be explained by longer time till measurement of titers in nonlactating group, allowing antibodies to reach their full peak.Regarding human milk, there was an IgA dominant response in women that were infected with SARS-CoV-2 [19]. A modest response of antibodies in human milk with an IgG dominant response was demonstrated. IgA titers, although present, decreased by the time of the second dose and no IgM was detected. When comparing titers of antibodies in serum and milk at the same time point, a similar response between them was noticed, although, lower levels of antibodies were present in the milk.

The dominant IgG response in blood and milk after COVID-19 vaccination can be related to an exposition of viral spike protein through an intramuscular injection. Contrarily, greater IgA response is registered in natural

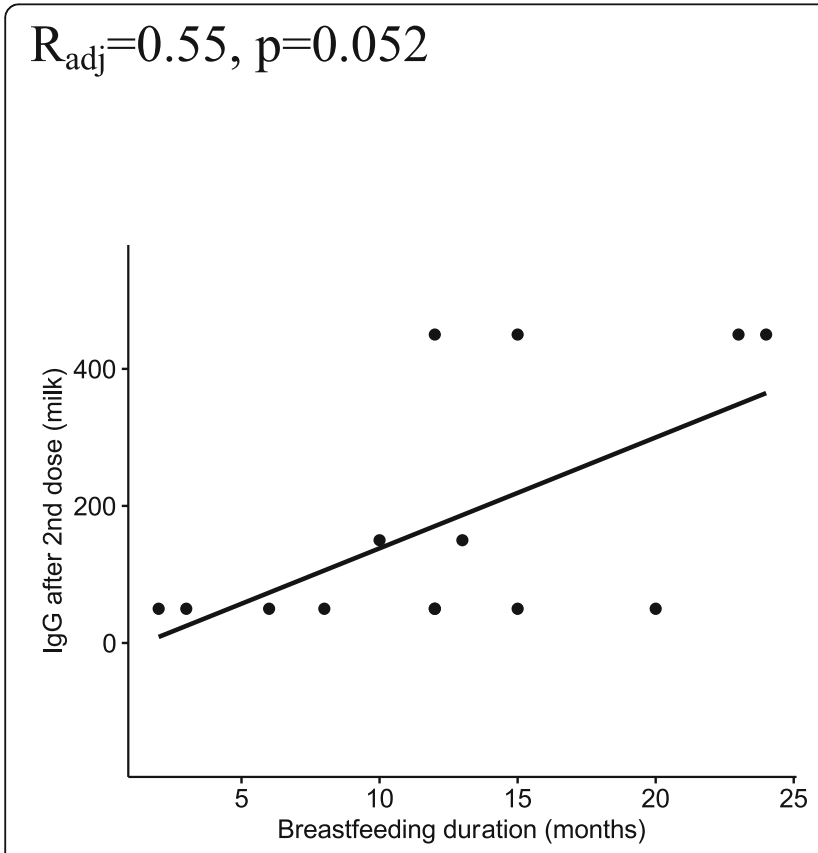

a)
$\mathrm{R}_{\mathrm{adj}}=-0.08, \mathrm{p}=0.069$

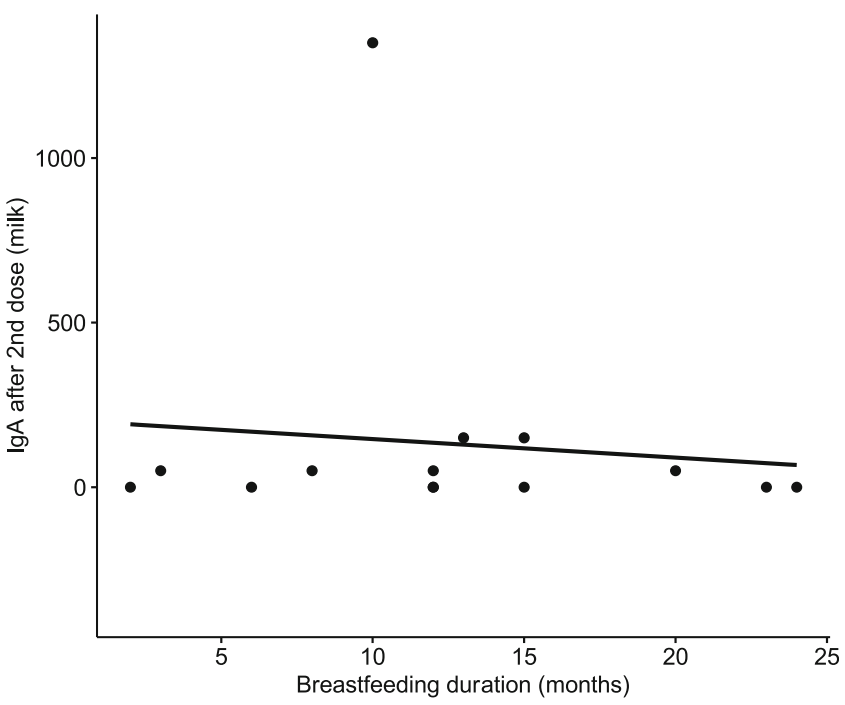

b)

Fig. 4 a Correlation between breastfeeding duration and milk $\lg \mathrm{G}$ after $2^{\text {nd }}$ dose. $\mathbf{b}$ Correlation between breastfeeding duration and milk $\lg \mathrm{A}$ after $2^{\text {nd }}$ dose 
infection, probably due to the fact that infection occurs in mucosal tissues where IgA response plays an important role. The mean value of IgG titers after the first dose (Fig. 2) for non-lactating women is higher than the lactating group due to the inclusion of an outlier value. This individual was maintained so not to reduce the sample size further. The fact that after the $2^{\text {nd }}$ dose, other individuals reached the same magnitude of titers indicates that the value is not itself senseless, but the sample size is small to encompass such variations. The comparison of the values distribution in both groups after the first dose showed that, in fact, non-lactating women had significantly higher levels of IgG antibodies.

During lactation, the immunological profile of human milk changes over time. SIgA is very high in colostrum, decreasing and remaining stable until 1 year of lactation. After this period, SIgA and IgG show an upward trend and IgM remains stable, supporting the importance of breastfeeding after one year of age for its immunological protection. These results might be associated with the higher production of antibodies in lactation over 12 months already demonstrated in other studies [20]. A correlation was also found between higher titter of antibodies in human milk in women that were breastfeeding for a longer time, although not significant after adjusting for maternal age and days after vaccine administration.

Further research is needed for a better knowledge of longevity of these antibodies in breastmilk and if they are transferred efficiently to the infant.

\section{Strengths and limitations}

One of the strengths of this study is related to the novelty of the topic, since little is known about COVID-19 vaccine immunization and breastfeeding. As breastfeeding brings so many advantages to the newborn and infant, it was considered of extreme importance, studies regarding vaccine and immune response in this population. This is the first study to compare the duration of breastfeeding with higher levels of antibodies in maternal milk.

In terms of limitations, previous infection to SARSCoV-2 could not be ruled out, as no antibody testing was performed before vaccination. However, participant self-reported that they were not previously infected and as they are health workers they are routinely tested. The small sample size limited statistical inference.

The increased levels of antibodies in non-lactating women after first dose was higher than in the lactating group probably due to a longer time until sample collection.

More than $90 \%$ of the human population is seropositive for at least three Human Coronavirus; therefore cross reactivity can also be an issue as it is speculated that this reflects $\mathrm{T}$ cell memory to circulating 'common cold' coronaviruses [21].

\section{Conclusion}

Currently, the evidence of antibodies transfer in human milk after COVID-19 vaccination is scarce. This is a first insight into vaccination and lactation, highlighting the questions that need to be answered. Also, the belief is, as per the findings, that long-term lactating women may show different serological milk responses after vaccination. Clinical trials are immediately required in this specific population in order to address scientific based recommendations.

\begin{abstract}
Acknowledgments
We thank Florian Krammer (Icahn School of Medicine at Mount Sinai, New York, USA) for kindly providing SARS-CoV-2 spike expression plasmids and Paula Alves, Pedro Cruz and Rute Castro from IBET for protein production and the support.
\end{abstract}

\section{Authors' contributions}

Team selection and facilitator performed by Helena Canhão. Selection of patients and study design perfomed by Nadia Charepe and Fátima Serrano. Sample collection done by Nadia Charepe, Juliana Gonçalves and Ana Margarida Juliano. Laboratory Methods written and executed by Juliana Gonçalves, Ana Margarida Juliano and Helena Soares. Data collection and questionaires done by Nadia Charepe and Fátima Serrano. Main manuscript written by Nadia Charepe. All Figures were prepared by David Lopes. All authors reviewed and approved the manuscript.

\section{Funding}

This work was supported by Gilead Génese (PGG/009/2017) and the European Society for Clinical Microbiology and Infectious Diseases (ESCMID) to HS. HS and JG is supported by FCT through CEECIND/01049/2020 and $\mathrm{PD} / \mathrm{BD} / 128343 / 2017$, respectively. ELISA assay was developed in the context of a Serology4COVID consortium, in which Instituto de Biologia Experimental e Tecnológica (IBET) produced and purified the Spike protein. The present publication was funded by Fundação Ciência e Tecnologia, IP national support through CHRC (UIDP/04923/2020).

\section{Availability of data and materials}

The datasets used and/or analyzed during the current study are available from the corresponding author on reasonable request.

\section{Declarations}

\section{Ethics approval and consent to participate}

This study was reviewed and approved by the local ethics committee (NOVA Medical School) as per principles embodied in the Declaration of Helsinki. Written informed consent was given by all participants.

\section{Consent for publication}

Not applicable.

\section{Competing interests}

I declare that the authors have no competing interests as defined by BMC, or other interests that might be perceived to influence the results and/or discussion reported in this paper.

\section{Author details}

${ }^{1}$ Centro Hospitalar Universitário de Lisboa Central (CHULC), Lisboa, Portugal. ${ }^{2}$ Comprehensive Health Research Centre, NOVA Medical School, Universidade NOVA de Lisboa, Lisboa, Portugal. ${ }^{3}$ Human Immunobiology and Pathogenesis Laboratory, Lisbon, Portugal. ${ }^{4}$ CEDOC-Chronic Diseases Research Center NOVA Medical School | Faculdade de Ciências Médicas, NOVA University of Lisbon, Lisbon, Portugal. ${ }^{5}$ EpiDoC Unit, CEDOC, NOVA Medical School, Universidade NOVA de Lisboa, Lisboa, Portugal. 
Received: 8 April 2021 Accepted: 12 August 2021

Published online: 17 September 2021

\section{References}

1. Palmeira P, Carneiro-Sampa PM. Immunology of breast milk. Rev Assoc Med Bras. 2016;62(6):584-93. https://doi.org/10.1590/1806-9282.62.06.584.

2. Jackson K, Nazar A. Breastfeeding, the Immune Response, and Long-term Health. J Am Osteopath Assoc. 2006;106:203-7 https://www.researchgate. net/publication/7152396_Breastfeeding_the_Immune_Response_and_Longterm_Health.

3. Demers-Mathieu V, Mathijssen GB, DaPra C, Do DM, Medo E. Active free secretory component and secretory IgA in human milk: do maternal vaccination, allergy, infection, mode of delivery, nutrition and active lifestyle change their concentrations? Pediatr Res. 2020;20:1-8. https://doi.org/10.103 8/s41372-021-01001-0.

4. Bradley T, Grundberg E, et al. Antibody Responses after a Single Dose of SARS-CoV-2 mRNA Vaccine. N Engl J Med. 2021. https://doi.org/10.1056/ NEJMC2102051.

5. Stuebe A. Considerations for COVID-19 Vaccination in Lactation. Breastfeed Med. 2020;16:1. https://doi.org/10.1089/bfm.2020.29172.abm.

6. COVID-19 Vaccination Considerations for Obstetric-Gynecologic Care. Practice Advisory, ACOG, updated 30 of July, 2021

7. Gray K, Bordt E, et al. COVID-19 vaccine response in pregnant and lactating women: a cohort study. medRxiv. 2021. https://doi.org/10.1016/j.ajog.2021. 03.023ajog.

8. Stadlbauer D, Amanat F, et al. SARS-CoV-2 Seroconversion in Humans: A Detailed Protocol for a Serological Assay, Antigen Production, and Test Setup. Curr Protoc Microbiol. 2020;57:1-15. https://doi.org/10.1002/cpmc.1 00

9. Stadlbauer D, Tan J, Jiang K, et al. Repeated cross-sectional sero-monitoring of SARS-CoV-2 in New York City. Nature. 2020. https://doi.org/10.1038/s41 586-020-2912-6.

10. Gonçalves J, Sousa RL, et al. Evaluating SARS-CoV-2 Seroconversion Following Relieve of Confinement Measures. Front Med. 2020;7:1-10. https://doi.org/10.3389/fmed.2020.603996

11. RStudio Team (2020). RStudio: Integrated Development for R. RStudio, PBC Boston, MA URL http://www.rstudio.com/.

12. Baird J, Jensen $\mathrm{S}$, et al. SARS-CoV-2 antibodies detected in human breast milk postvaccination. medRxiv. 2021; https://www.medrxiv.org/content/1 0.1101/2021.02.23.21252328v2.

13. Campillo-Luna J, Wisnewski A, et al. Human lgG and lgA responses to COVID-19 mRNA vaccines. medRxiv. 2021. https://doi.org/10.1101/2021. 03.23.21254060.

14. Esteve-Palau E, Gonzalez-Cuevas A, et al. Quantification of specific antibodies against SARS-CoV-2 in breast milk of lactating women vaccinated with an mRNA vaccine. medRxiv. 2021. https://doi.org/10.1101/2 021.04.05.21254819.

15. Ertrand K, Honerkamp-Smith G, Chambers C. Maternal and child outcomes reported by breastfeeding women following mRNA COVID-19 vaccination. medRxiv. 2021. https://doi.org/10.1101/2021.04.21.21255841.

16. Golan Y, Prahl M, et al. COVID-19 mRNA vaccine is not detected in human milk. medRxiv. 2021. https://doi.org/10.1101/2021.03.05.21252998.

17. Friedman M, Kigel A, et al. BNT162b2 COVID-19 mRNA vaccine elicits a rapid and synchronized antibody response in blood and milk of breastfeeding women. medRxiv. 2021. https://doi.org/10.1101/2021.03.06.21252603.

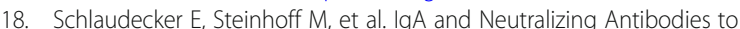
Influenza A Virus in Human Milk: A Randomized Trial of Antenatal Influenza Immunization. PLoS One. 2013;8(8):e70867. https://doi.org/10.1371/journal. pone.0070867

19. Fox A, Marino J, et al. Evidence of a significant secretory-lgA-dominant SARS-CoV-2 immune response in human milk following recovery from COVID-19. medRxiv. 2020. https://doi.org/10.1101/2020.05.04.20089995.

20. Czosnykowska-Łukacka M, Lis-Kuberka J, et al. Changes in Human Milk Immunoglobulin Profile During Prolonged Lactation. Front Pediatr. 2020;8: 428. https://doi.org/10.3389/fped.2020.00428.

21. Sette,A., Crotty, S. Pre-existing immunity to SARS-CoV-2: the knowns and unknowns (2020) Nat Rev Immunol 20. https://doi.org/10.1038/s41577-0200389-z

\section{Publisher's Note}

Springer Nature remains neutral with regard to jurisdictional claims in published maps and institutional affiliations.

\section{Ready to submit your research? Choose BMC and benefit from}

- fast, convenient online submission

- thorough peer review by experienced researchers in your field

- rapid publication on acceptance

- support for research data, including large and complex data types

- gold Open Access which fosters wider collaboration and increased citations

- maximum visibility for your research: over $100 \mathrm{M}$ website views per year

At BMC, research is always in progress.

Learn more biomedcentral.com/submissions 